\title{
Radiofrequency ablation of lung tumours
}

\author{
Irene Bargellini • Elena Bozzi • Roberto Cioni • \\ Barbara Parentini • Carlo Bartolozzi
}

Received: 11 October 2010 / Revised: 17 March 2011 / Accepted: 8 June 2011 /Published online: 20 July 2011

(C) European Society of Radiology 2011

\begin{abstract}
Pulmonary radiofrequency ablation (RFA) has become an increasingly adopted treatment option for primary and metastatic lung tumours. It is mainly performed in patients with unresectable or medically inoperable lung neoplasms. The immediate technical success rate is over $95 \%$, with a low periprocedural mortality rate and $8-12 \%$ major complication rate. Pneumothorax represents the most frequent complication, but requires a chest tube drain in less than $10 \%$ of cases. Sustained complete tumour response has been reported in $85-90 \%$ of target lesions. Lesion size represents the most important risk factor for local recurrence. Survival data are still scarce, but initial results are very promising. In patients with stage I nonsmall-cell lung cancer, 1- and 2-year survival rates are within the ranges of $78-95 \%$ and $57-84 \%$, respectively, with corresponding cancer-specific survival rates of $92 \%$ and $73 \%$. In selected cases, the combination of RFA and radiotherapy could improve these results. In patients with colorectal lung metastasis, initial studies have reported survival data that compare favourably with the results of metastasectomy, with up to a $45 \% 5$-year survival rate. Further studies are needed to understand the potential role of RFA as a palliative treatment in more advanced disease and the possible combination of RFA with other treatment options.
\end{abstract}

Keywords Radiofrequency A Ablation · Lung neoplasm · Solid tumour

I. Bargellini $(\triangle) \cdot$ E. Bozzi $\cdot$ R. Cioni $\cdot$ B. Parentini $\cdot$

C. Bartolozzi

Department of Diagnostic and Interventional Radiology, Pisa

University Hospital,

Via Paradisa 2,

56124 Pisa, Italy

e-mail: irenebargellini@homail.com

\section{Introduction}

Radiofrequency ablation (RFA) is nowadays the most widely used ablative treatment, and it is considered the treatment of choice in the liver for inoperable patients with early primary or secondary neoplastic disease [1].

In the lung, initial experiments in animal models have demonstrated that RFA can destroy a controlled area of both healthy pulmonary tissue and experimentally induced lung malignancy [2, 3]. A given quantity of RF current delivered into the lung produces a larger volume than in subcutaneous tissues or in the kidney, probably as a result of heat insulation and low electric conductivity provided by the lung surrounding the tumour.

Since the advent of these initial experimental models, the interest in this treatment technique has increased worldwide and, today, lung RFA has become established in selected patients in many institutions, providing high local tumour control rates [4-7].

This article provides an overview of the current status of lung RFA in terms of indications, technique, complications and results.

\section{Indications}

Currently, RFA is indicated in patients with primary or secondary lung tumours (in particular, from colorectal cancer) that are considered inoperable, either for medical conditions or for unfavourable tumour location $[8,9]$.

Patient selection for RFA should be carefully performed by a multidisciplinary team [9]. Preprocedural clinical and imaging workup is required to assess indications, stage the tumour, exclude contraindications (such as uncorrected 
coagulopathy) and plan the treatment, with particular reference to the needle trajectory.

Biopsy is required in patients suspected of having primary lung cancer or in patients with lung metastasis with atypical imaging appearances. Biopsy should generally be performed before RFA, unless the patient is considered to be at very high risk, in which case biopsy and RFA could be performed in one setting.

\section{Non-small-cell lung cancer}

Standard of care for stage I non-small-cell lung cancer (NSCLC) is represented by surgical resection. However, only about one-third of patients are eligible for surgical intervention.

Sublobar resections may represent an alternative to lobectomy in patients with limited cardiopulmonary reserve, thanks to technical improvements that have increased local tumour control and survival rates [10].

Conventional radiotherapy, stereotactic body radiotherapy and RFA can also be offered to medically inoperable stage I NSCLC patients. A recent retrospective nonrandomised study carried reported comparable survival rates after sublobar resection, RFA or percutaneous cryoablation in a series of 64 patients who were deemed not to be candidates for lobectomy [10]. Thus, percutaneous ablative treatments can represent valid minimally invasive alternatives in inoperable patients.

Radiofrequency ablation can also be a reasonable option at more advanced stages of the disease, such stages III and $\mathrm{IV}$, in the presence of a satellite nodule in the same lobe or in a different ipsilateral or contralateral lobe. Moreover, RFA can be offered in stage III or IV patients who have a persistent solitary nodule after radiation or chemotherapy. Finally, RFA represents a valid option in recurrent isolated lesions after lung resection [8], keeping in mind that percutaneous treatments in patients who have undergone previous lobectomy may be associated with higher incidence of periprocedural complications.

In a curative intent, indications for RFA are strictly dependent on anatomical criteria, such as nodule size and location. In fact, lesions larger than $5 \mathrm{~cm}$ should be excluded from RFA, whereas lesions from 3 to $5 \mathrm{~cm}$ should be considered with caution because of the high incidence of recurrence [11]. Moreover, nodules located less than $1 \mathrm{~cm}$ from the trachea, main bronchi, oesophagus and central vessels should be excluded, as they are considered at high risk of complications and can often not be completely ablated.

\section{Lung metastases}

Lung is the second most frequent site of metastases. RFA has become a reasonable treatment option in non-surgical patients with limited pulmonary metastatic involvement, particularly for colorectal cancer [8]. It is generally accepted that RFA should be performed in the presence of less than five lesions per hemithorax. However, this does not represent an absolute criterion, as long as all the lesions can be successfully ablated.

Percutaneous ablation is also an interesting minimally invasive option in patients with recurrent disease after a previous resection.

As for primary lung tumours, tumour size $(<5 \mathrm{~cm}$, ideally $<3.5 \mathrm{~cm}$ ) and location $(>1 \mathrm{~cm}$ trachea, main bronchi, oesophagus, central vessels) are important determinants for RFA.

\section{Procedure}

The RF is a sinusoidal current with a frequency of 400 to $500 \mathrm{kHz}$ that heats tissues through ionic agitation. It induces a thermal destruction of tissues by heating cells to $>60^{\circ} \mathrm{C}$ obtaining a non-reversible cellular modification, called "coagulative necrosis" [12]. The goal of ablative techniques is to obtain and maintain a temperature from $50^{\circ}$ $\mathrm{C}$ to $100^{\circ} \mathrm{C}$ through the target volume by the percutaneous insertion of a needle.

In the specific setting of pulmonary ablation, the intrinsic characteristics of lung tissue interfere with the energy delivery more than in other tissues, e.g. liver. For this reason, different methods have been developed to improve the energy-tissue interaction, to increase the RFA volume by a single delivery and, ultimately, to treat larger lesions. Initially, the singleneedle electrode was implemented by the simultaneous application of multiple probes; nevertheless, the precise positioning of more than two electrodes was technically complex. Thus, expandable, cooled and bipolar needles have been introduced for treating lung lesions.

Expandable needles are the most commonly used devices in lung RFA. They contain several (8-12) electrodes that are deployed into the target tissue in a single insertion. Each electrode produces a small area of ablation; the summation of all the areas determines the destruction of a larger portion of tumour. The number of deployable electrodes and the degree of deployment can vary according to the desired volume of ablation.

The cooled-tip electrode consists of a double-lumen needle in which the electrode is cooled with chilled water. This technique increases the current delivered, without boiling the tissue close to the needle, where the current density is very high.

Finally, the micro-perfused electrodes take advantage of enhanced RF delivery with the help of saline perfusion. The administration of fluid solution into the tissue during the thermal ablation increases the electrical conductivity, obtaining larger ablation volumes in shorter times [13]. 
In RFA, the patient is part of a closed-loop circuit. Therefore, any electrode requires the placement of dispersive electrodes (ground pads) on the patient's thighs.

Lung RFA has to be performed under anaesthesiological care. There is no consensus in the literature regarding the best anaesthesiological technique during RFA, taking into account that most selected patients carry a medium to high anaesthesiology risk. Choice of sedation may depend on the patient's status and tumour treated; thus, different techniques should be taken into consideration. Hoffmann et al. reported similar results, in terms of feasibility, complication rate, hospitalisation and local tumour control, after general anaesthesia or conscious sedation, and concluded that conscious sedation should be preferred, reserving general anaesthesia for non-compliant patients [14]. However, other authors reported lower feasibility rates and higher periprocedural pain after conscious sedation compared with general anaesthesia $[15,16]$.

Computed tomography is currently the only accurate imaging technique for guidance during lung RFA. The correct planning of the needle track is a key factor for technical success. The path should be the shortest possible, and it should avoid interlobar fissures, bullae and vessels. Multiplanar reconstructions before current delivery are mandatory to assess adequate electrode positioning relative to tumour margins in all planes (Fig. 1).

Radiofrequency delivery has to be adapted to the tumour location, which can cause variation in impedance. In fact, the tumour surrounded by lung parenchyma is electrically and thermally insulated by the air-filled lung compared with the tumour abutting the pleura, which requires more energy deposition [17]. Moreover, subpleural tumours can be difficult to puncture; an artificially induced pneumothorax has been proposed as a means of separating the subpleural tumour from the pleura or the mediastinum [18].

After probe removal, a CT is required to exclude immediate complications, such as pneumothorax, and to estimate the area of ablation. The presence of an area of ground-glass opacity around the tumour margins is reported to be indicative of adequate tumour ablation with safety ablation margins (Fig. 2) [19].

\section{Complications}

Radiofrequency ablation of lung tumours is a relatively safe procedure, with low mortality (around $0.4 \%$ ) and excellent tolerance in terms of respiratory function, although the reported periprocedural morbidity rate ranges from $15.5 \%$ to $55.6 \%$ (median 35.7\%), with an 8-12\% major complication rate [20].

Complications can be classified depending on their severity, according to the SIR grading system on a persession basis [21]. Moreover, they can be divided into periprocedural and postprocedural complications.
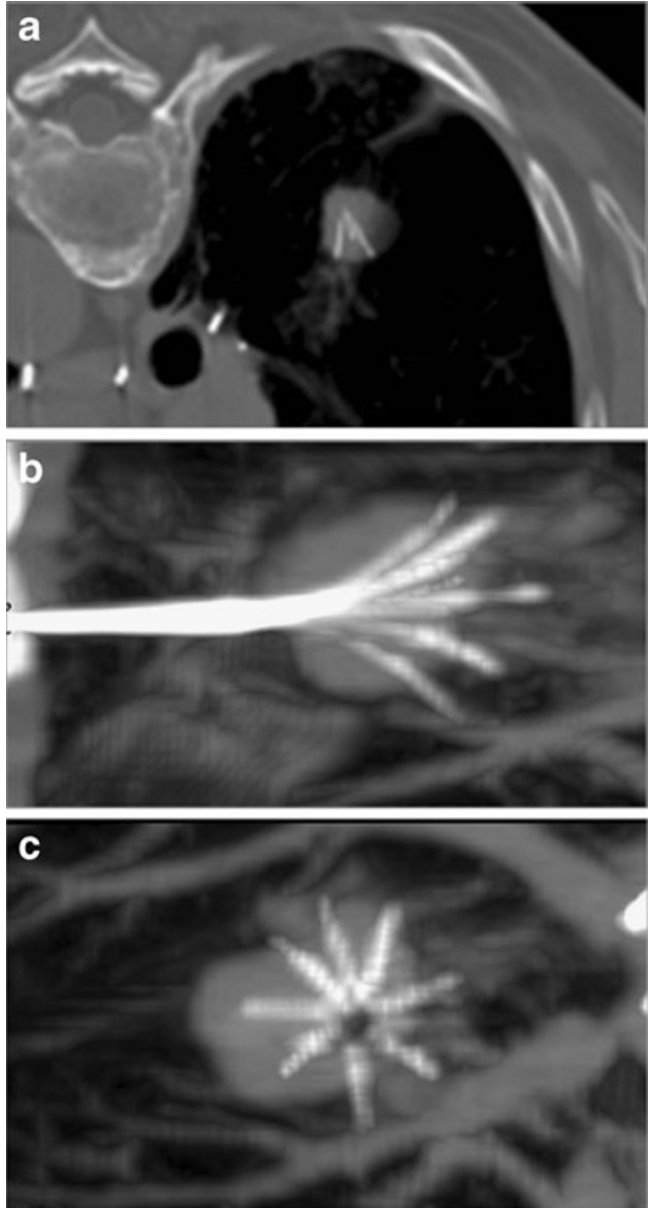

Fig. 1 Primary lung tumour located in the right lower lobe and treated by RFA. The axial CT shows adequate positioning of the needle within the nodule. Multiplanar reformations demonstrate that the needle is not correctly positioned in the centre of the nodule $(B, C)$

The most common periprocedural complication is pneumothorax, occurring in up to $60 \%$ of ablation sessions. Most cases of pneumothorax do not require any treatment, whereas in about $20 \%$ of procedures pneumothorax can be solved immediately after RFA by insertion of a small needle catheter. Only about $4 \%$ to $12 \%$ of procedures require chest tube drainage (Fig. 3) [17]. Reported risk factors for the development of pneumothorax are previous pulmonary surgery (although this result has not been confirmed in all studies), emphysema, the increased length of the aerated lung traversed by the electrode, the mean number of ablated tumours and the number of electrode positioning [22-24].

Intractable pneumothorax due to bronchopleural fistula has been reported in about $0.6 \%$ of cases [25].

Small reactive pleural effusions are commonly found, usually resolving spontaneously, whereas pleural effusion requiring chest tube drainage is a rare event.

Similarly, parenchyma haemorrhage can occur in approximately $8-10 \%$ of ablations and tends to solve spontaneously 
Fig. 2 Primary lung tumour located in the right lower lobe (A). The CT control performed immediately after RFA shows a large area of ground glass surrounding the nodule $(\mathrm{B})$; the needle was slightly to the right of centre of the nodule
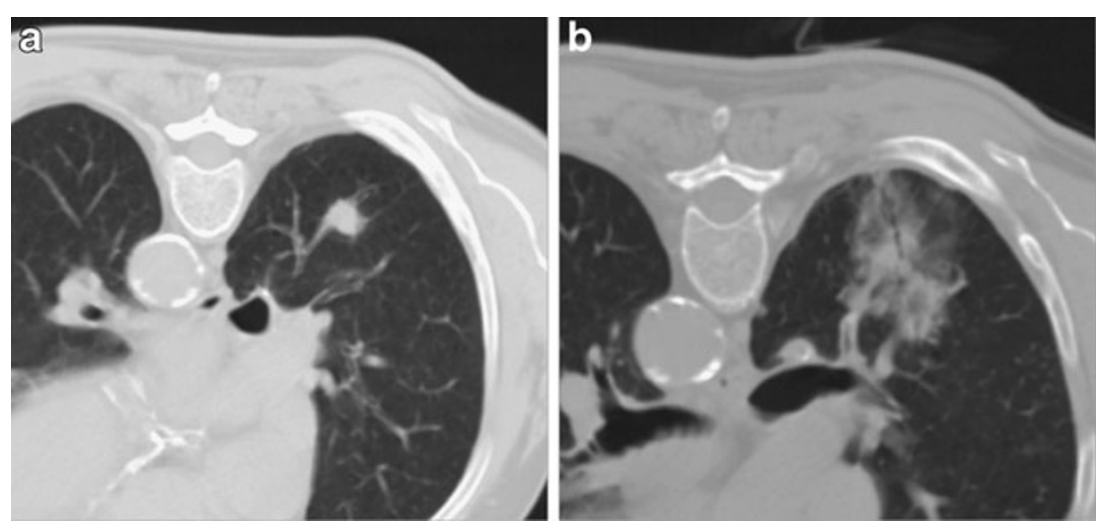

in most cases (Fig. 4). In up to $15 \%$ of patients minor selflimiting hemoptysis can occur, whereas more severe haemorrhage is a rare event that can occur in tumours in contact with the hilum. Delayed major haemorrhage has also been reported, caused by the development of false aneurysms of the pulmonary artery and requiring coil embolisation [26].
Other reported complications are subcutaneous emphysema, infection and pulmonary abscesses (Fig. 5).

Tumour seeding along the needle tract is a very rare complication. Although unproven, track ablation at the end of the procedure is recommended to reduce the risk of seeding [27].
Fig. 3 Subpleural primary lung tumour in the right lower lobe (A). The CT control during RFA demonstrates correct placement of the needle with a minimal area of pneumothorax (B). The $\mathrm{CT}$ control performed at the end of the procedure shows a large pneumothorax $(\mathrm{C})$ that required chest tube drainage (D)

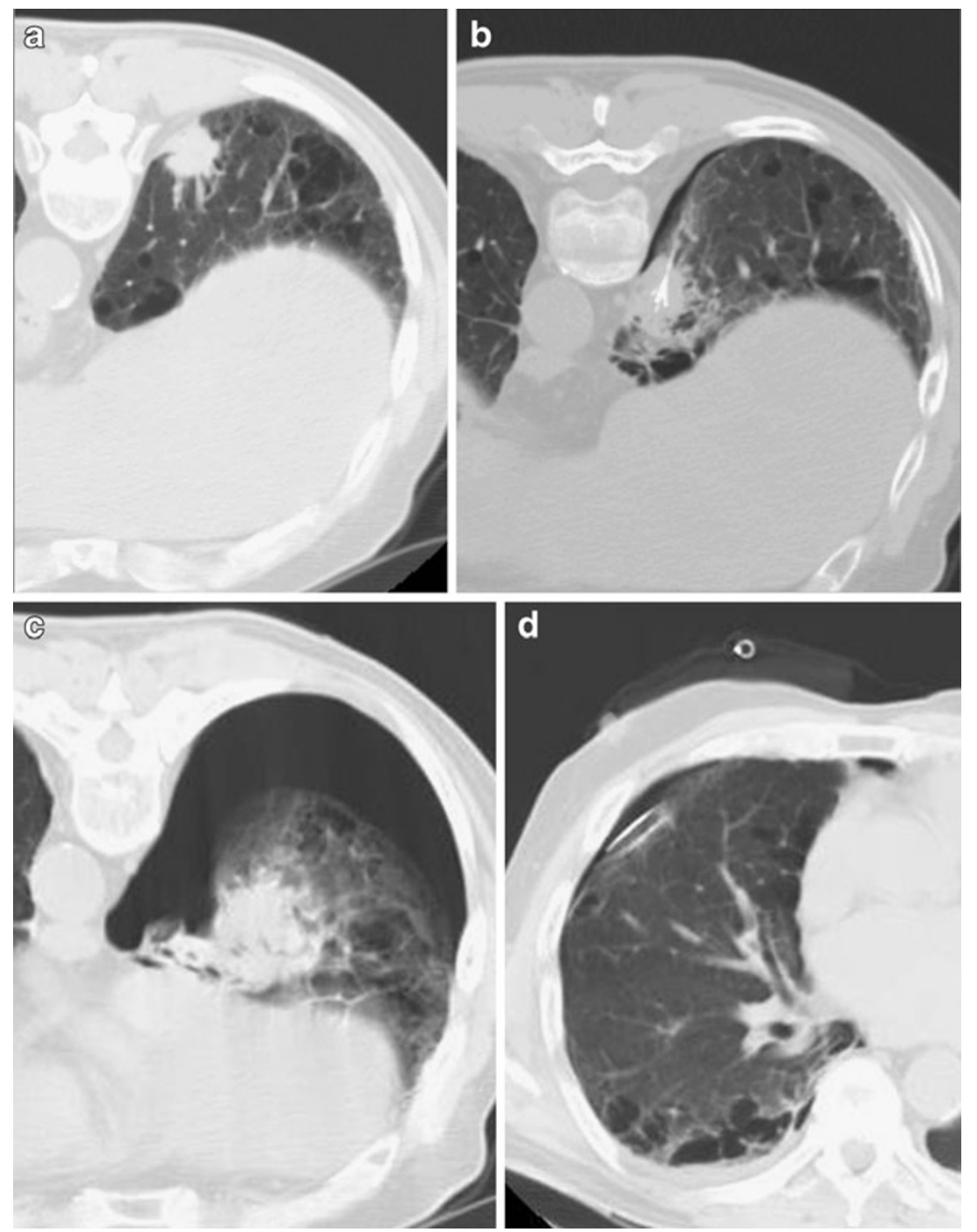




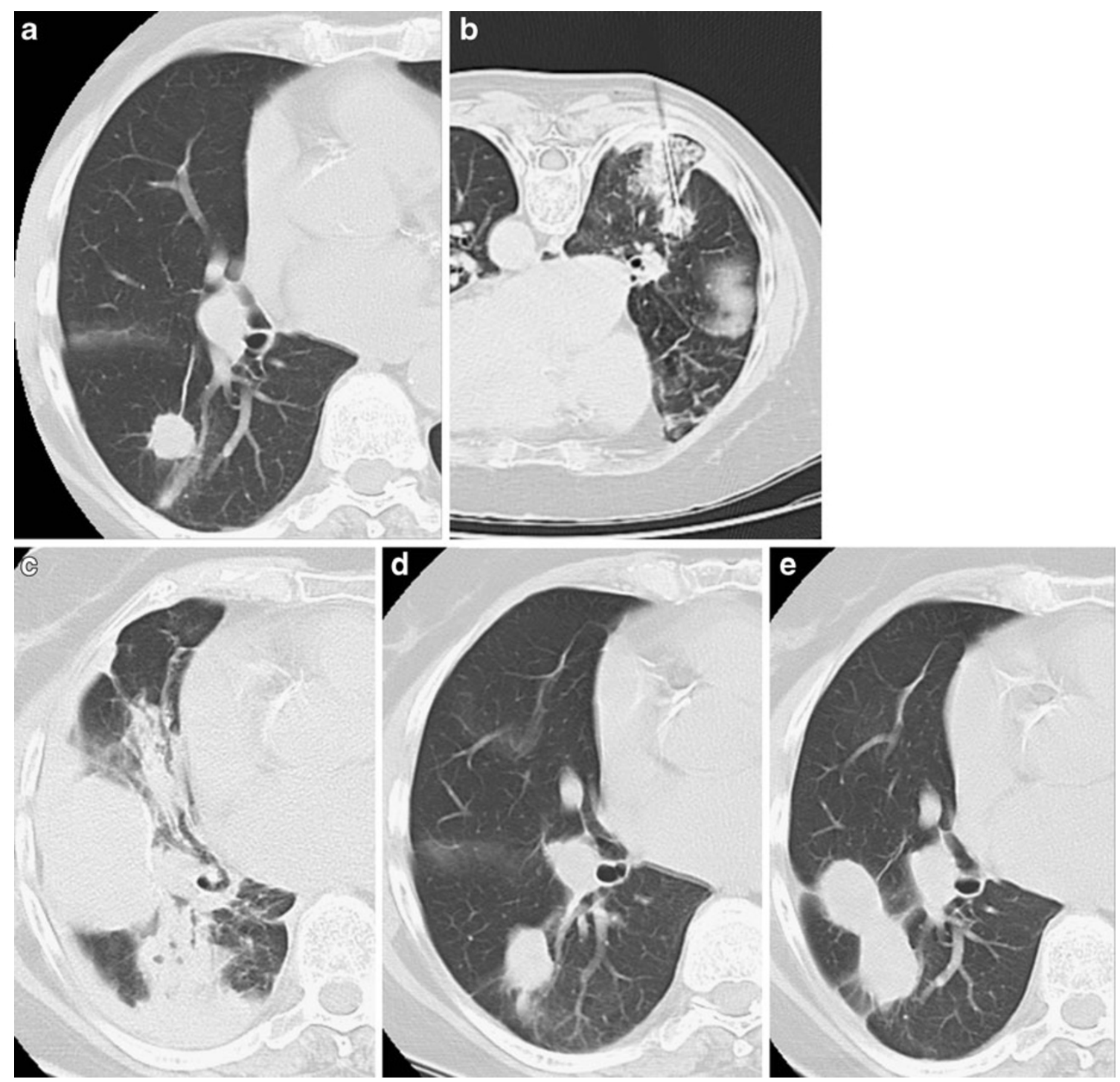

Fig. 4 Primary lung tumour in the right upper lobe (A). The CT control during RFA demonstrates correct placement of the needle with a limited area of parenchymal haemorrhage (B). The CT control performed at the end of the procedure shows pleural effusion and a consolidation corresponding to parenchyma haemorrhage (C) without

Although the procedure is well tolerated, RFA is associated with a number of side effects. Mild to moderate periprocedural and postprocedural pain are frequently reported, lasting up to 7 days and requiring oral analgesics, to prevent dyspnoea. Also, raised body temperature (up to $38^{\circ} \mathrm{C}$ ) is common in the periprocedural period.

\section{Imaging follow-up and tumour response}

Target tumour response is most frequently assessed by computed tomography (CT).

As the aim of RFA is to produce a volume of coagulative necrosis larger than the native nodule, CT performed in the haemoptysis. No adjunctive procedures were required and the CT controls performed 3 (D) and 6 months (E) after treatment documented progressive reduction of the consolidation and shrinkage of the tumour nodule

first month after the procedure should demonstrate a hyperattenuating area larger than the treated nodule.

The ablation zone should then progressively shrink as early as 2 to 3 weeks after treatment (Fig. 6) [17].

Cavitation of the ablation zone has been described in up to $30 \%$ of ablations and seems to occur more frequently when the lesion is in contact with a segmental bronchus (Fig. 6) [28].

Follow-up usually includes contrast-enhanced CT of the lung 1 month after the procedure and every 3 months thereafter. Recurrences can occur as long as 2 years after treatment; thus, continued imaging follow-up is needed [11].

Up to now, no universal agreement has been reached regarding the most proper criteria to assess tumour response after lung RFA. 


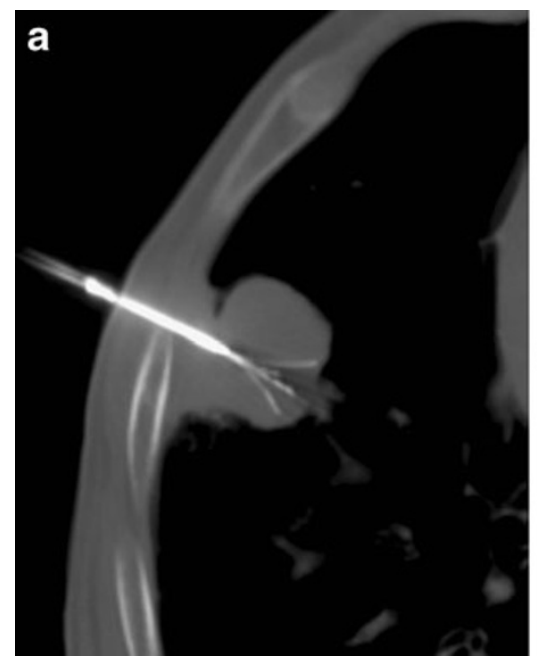

Fig. 5 Subpleural lung tumour treated by RFA (A). The CT control performed 9 months after treatment depicted a subcutaneous mass adjacent to the tumour with peripheral enhancement and air bubbles.

It is generally accepted that a completely ablated tumour should not increase in size on subsequent imaging. However, relying exclusively on tumour size implies a late discovery of incomplete treatment and local recurrence $[5$, $11]$.

Amended RECIST criteria have therefore been proposed, taking into account not only the lesion size, but also tumour geometry and contrast enhancement. In a large multicenter trial, complete response was defined as a decrease in the longest diameter of at least $30 \%$ compared with the diameter measured at the 1-month $\mathrm{CT}$ examination, with no evidence of peripheral tumour growth and no evidence of contrast enhancement [7]. Also, cyst and cavity formation have been regarded as indicative of complete response (Fig. 6) [8].

Nonetheless, the tumour enhancement after lung RFA seems to be less informative than for other tumours, such as hepatocellular carcinoma. In a recent pilot experimental study, diffusion MRI has demonstrated promising results in identifying complete tumour response [29]; nonetheless, these results need further confirmation and the usefulness of this imaging technique is limited in the case of small pulmonary nodules.

To avoid the late diagnosis of incomplete ablation, PET$\mathrm{CT}$ has been proposed in some centres [8, 17, 30, 31], providing higher sensitivity and specificity than $\mathrm{CT}$ in depicting residual viable tumour. Okuma et al. demonstrated that the timing of PET after RFA is a key factor. In fact, fluorine-18 fluorodeoxyglucose uptake is highly increased 1 to 3 weeks after ablation, because of the post-treatment inflammatory reaction, and, therefore, at least a 4-week interval is required to avoid false-positive results $[30,31]$.

However, the use of PET in post-RFA follow-up is still limited in clinical practice.
Under suspicion of a secondary location (tumour seeding), biopsy was performed (C), allowing the final diagnosis of an abscess formation involving the treated lesion with extension to the thoracic wall

The lack of universally adopted criteria to assess tumour response could explain the heterogeneity of published results in terms local tumour control rate, which ranges from $38 \%$ to $97 \%$, with a median reported rate of complete ablation of $90 \%$ [32].

In a recently published series of 91 patients with NSCLC treated by RFA followed for 1-72 months, tumour recurrence was observed in $43 \%$ of patients, and the most common pattern of recurrence was local [11], suggesting the need for more aggressive initial ablation treatment and underlining the potential role of adjuvant radiation as a means of improving local tumour control, particularly in larger tumours [33, 34].

Negative predictive factors of complete tumour ablation are tumour size larger than $3 \mathrm{~cm}$ and contact with large vessels $[5,7,35-37]$.

\section{Survival}

Survival data after lung RFA are still scarce, with few series providing survival beyond 3 years. Moreover, there are no prospective randomised studies comparing RFA with surgery, other ablative treatments or radiotherapy.

\section{Non-small-cell lung cancer}

Initial investigations report promising outcomes in patients with stage I NSCLC, with 1- and 2-year survival rates in the range of $78-95 \%$ and $57-84 \%$ respectively $[4,6,7,16$, $36,38]$, and about $36 \% 3$-year survival [6]. These data are encouraging and compare favourably with the results provided by conventional radiation therapy.

In a series of 75 primary NSCLC patients, Simon et al. reported median overall survival periods of 30 months at 
Fig. 6 Non-small-cell lung carcinoma (NSCLC) located in the right lower lobe, adjacent to a segmental bronchus (A). RFA was successfully performed (B). The 1-month CT control demonstrated a large area of cavitation including the entire nodule, with no significant contrast enhancement $(\mathrm{C}, \mathrm{D})$; the findings were considered indicative of complete response. The 6- and 12-month CT examinations (E, F) demonstrated the progressive reduction in size of the cavitation with formation of a fibrotic band, corresponding to a complete response to treatment
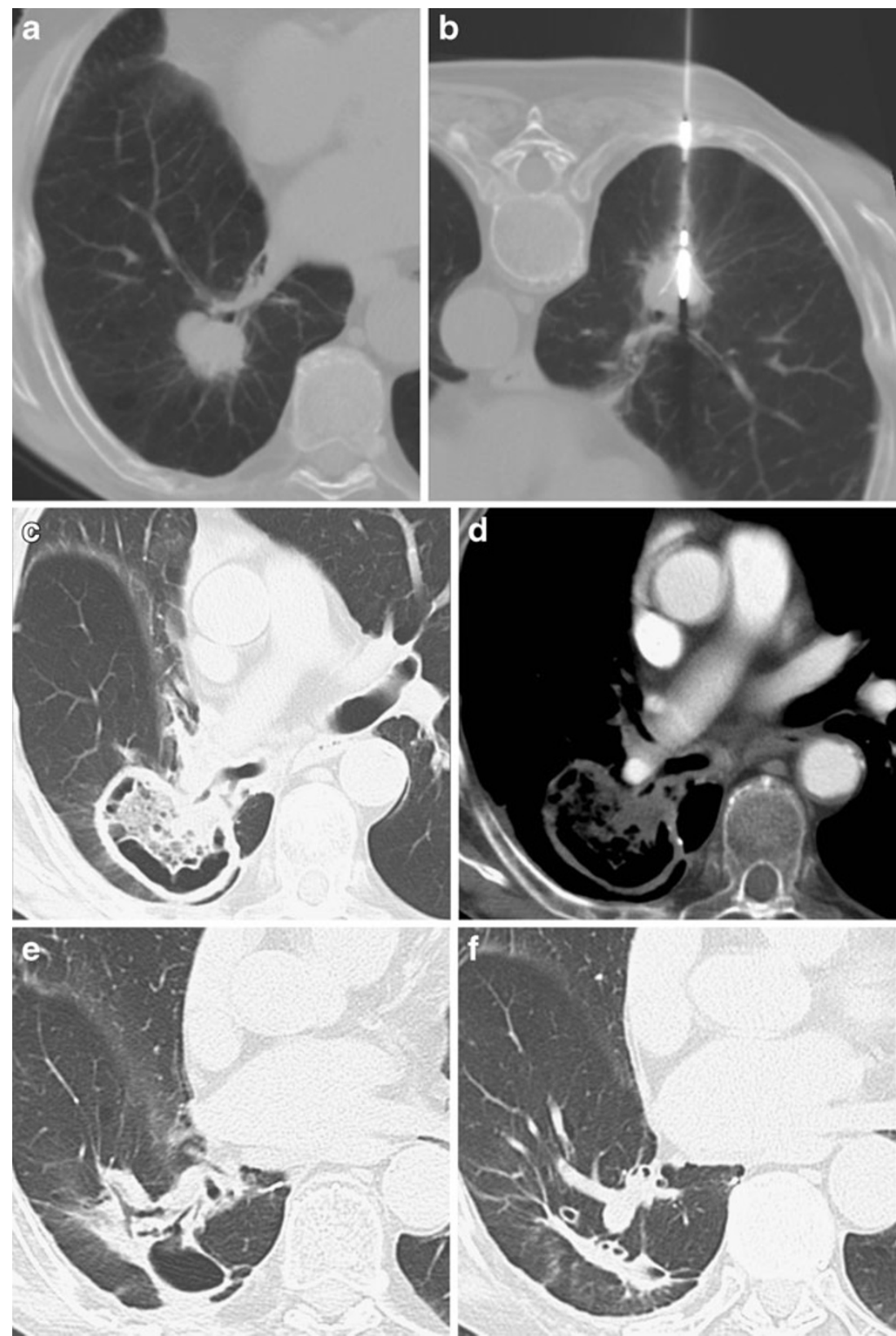

stage IA and 25 months at stage IB. Survival was significantly related to tumour size, with almost $50 \% 5$ year survival for tumours $\leq 3 \mathrm{~cm}$ [6]. This study did not report cancer-specific survival; thus, the effect of RFA itself was not specifically determined.

Conversely, the RAPTURE trial (the only prospective multicenter trial published to date) reported a striking difference between overall survival (70\% and $48 \%$ at 1 and 2 years, respectively) and cancer-specific survival (92\% and $73 \%$ at 1 and 2 years respectively), reflecting the role of comorbidities and poor pulmonary function in these patients who are selected for RFA after exclusion from surgery [7].

For larger tumours, the combination of RFA and radiotherapy could improve the results. In a series of 41 patients, Grieco et al. reported a 57\% 3-year survival rate [33], which represents an encouraging outcome.

\section{Colorectal lung metastases}

As for primary lung cancer, survival data after RFA of colorectal lung metastasis are encouraging, with survival rates of $54-78 \%$ and $46-57 \%$ at 2 and 3 years respectively [6, 7, 39].

Longer follow-up data have been recently published, reporting 5-year survival rates of $35-45 \%$ [40-42]. These results compare favourably with the 48\% 5-year survival rate reported after metastasectomy in a systematic review of 1,684 patients [43]. Predictive factors for survival after RFA are similar to those described after metastasectomy. 
According to Yamakado et al. [40], maximum tumour diameter less than $3 \mathrm{~cm}$, single-lung metastasis, lack of extrapulmonary metastasis and normal carcinoembryonic antigen (CEA) level are all positive prognostic factors for survival after RFA. In patients with no extrapulmonary metastases the 5-year survival rate was $57 \%$ and when both tumour size less than $3 \mathrm{~cm}$ and disease limited to the lung were present, the 3-year survival reached $78 \%$. Moreover, in patients with negative CEA levels survival at 5 years was $62.5 \%$.

Survival also seems to be influenced by the tumour response to RFA and by the association with systemic chemotherapy [42].

According to these data, in the setting of colorectal metastases, it is reasonable to compare RFA with metastasectomy.

\section{Conclusions}

In less than a decade, pulmonary RFA has become a highly appealing, minimally invasive treatment option that has been widely adopted in several centres to treat primary and secondary lung tumours.

In experienced hands, it is a safe technique with high local tumour control rates.

Indeed, according to the latest NICE (National Institute for Health and Clinical Excellence) guidelines [9], "the current evidence on the efficacy of percutaneous radiofrequency ablation (RFA) for primary or secondary lung cancers is adequate in terms of tumour control and safety; thus, the procedure should be considered in patients with small, early-stage lung cancers or small numbers of lung metastases who are unsuitable for, or prefer not to undergo, surgery".

In patients with primary NSCLC, surgery should remain the standard therapy. However, RFA is becoming a valid tool in specific clinical scenarios as a single treatment as well as in combination with other treatments, such as radiotherapy.

In the setting of colorectal lung metastases, RFA is associated with relatively high mid- and long-term survival rates, which are far better than those obtained with any chemotherapy regimen. Thus, it would be reasonable to compare the results of RFA with the outcomes of surgical resection.

There are several ongoing prospective trials that will further assess the long-term results of RFA in lung tumours [44]. Prospective randomised trials would also be desirable. For instance, there is a need to compare RFA with stereotactic radiation therapy. The latter has been proven to be associated with high local tumour control rates (up to $80 \%$ for secondary lesions and over $90 \%$ for stage I
NSCLC) and encouraging survival rates [45-47] and is being proposed as a valid alternative to surgery in selected patients.

Finally, the role of RFA as a palliative treatment in larger tumours or in more advanced disease deserves further investigation.

\section{References}

1. Bruix J, Sherman M (2005) AASLD PRACTICE GUIDELINE. Management of Hepatocellular Carcinoma. Hepatology 42 (5):1208-1236

2. Goldberg SN, Gazelle GS, Compton CC, McLoud TC (1995) Radiofrequency tissue ablation in the rabbit lung: efficacy and complications. Acad Radiol 2:776-784

3. Miao Y, Ni Y, Bosmans H, Yu J, Vaninbroukx J, Dymarkowski S, Zhang H, Marchal G (2001) Radiofrequency ablation for eradication of pulmonary tumor in rabbits. J Surg Res 99 (2):265-271

4. Fernando HC, De Hoyos A, Landreneau RJ, Gilbert S, Gooding WE, Buenaventura PO, Christie NA, Belani C, Luketich JD (2005) Radiofrequency ablation for the treatment of non-small cell lung cancer in marginal surgical candidates. J Thorac Cardiovasc Surg 129:639-644

5. de Baère T, Palussière J, Aupérin A, Hakime A, Abdel-Rehim M, Kind M, Dromain C, Ravaud A, Tebboune N, Boige V, Malka D, Lafont C, Ducreux M (2006) Midterm local efficacy and survival after radiofrequency ablation of lung tumors with minimum follow-up of 1 year: prospective evaluation. Radiology 240:587596

6. Simon CJ, Dupuy DE, DiPetrillo TA, Safran HP, Grieco CA, Ng T, Mayo-Smith WW (2007) Pulmonary radiofrequency ablation: long-term safety and efficacy in 153 patients. Radiology 243:268275

7. Lencioni R, Crocetti L, Cioni R, Suh R, Glenn D, Regge D, Helmberger T, Gillams AR, Frilling A, Ambrogi M, Bartolozzi C, Mussi A (2008) Response to radiofrequency ablation of pulmonary tumours: a prospective, intention-to-treat, multicentre clinical trial (the RAPTURE study). Lancet Oncol 9(7):621-628

8. Abbas G, Pennathur A, Landreneau RJ, Luketich JD (2009) Radiofrequency and microwave ablation of lung tumors. J Surg Oncol 100(8):645-650

9. http://www.nice.org.uk/nicemedia/live/11206/52082/52082.pdf

10. Zemlyak A, Moore WH, Bilfinger TV (2010) Comparison of survival after sublobar resections and ablative therapies for stage I non-small cell lung cancer. J Am Coll Surg 211(1):6872

11. Beland MD, Wasser EJ, Mayo-Smith WW, Dupuy DE (2010) Primary non-small cell lung cancer: review of frequency, location, and time of recurrence after radiofrequency ablation. Radiology 254(1):301-307

12. Goldberg SN, Gazelle GS, Mueller PR (2000) Thermal ablation therapy for focal malignancies: a unified approach to underlying principles, techniques, and diagnostic imaging guidance. AJR Am J Roentgenol 174:323-331

13. Crocetti L, Lencioni R, Bozzi E, Sbrana A, Bartolozzi C (2008) Lung radiofrequency ablation: in vivo experimental study with low-perfusion-rate multitined electrodes. Cardiovasc Intervent Radiol 31(3):610-618

14. Hoffmann RT, Jakobs TF, Lubienski A, Schrader A, Trumm C, Reiser MF, Helmberger TK (2006) Percutaneous radiofrequency ablation of pulmonary tumors. Is there a difference between 
treatment under general anaesthesia and under conscious sedation? Eur J Radiol 59:168-174

15. Yasui K, Kanazawa S, Sano Y, Fujiwara T, Kagawa S, Mimura H, Dendo S, Mukai T, Fujiwara H, Iguchi T, Hyodo T, Shimizu N, Tanaka N, Hiraki Y (2004) Thoracic tumors treated with CTguided radiofrequency ablation: initial experience. Radiology 231 (3):850-857

16. Lee JM, Jin GY, Goldberg SN, Lee YC, Chung GH, Han YM, Lee SY, Kim CS (2004) Percutaneous radiofrequency ablation for inoperable non-small cell lung cancer and metastases: preliminary report. Radiology 230(1):125-134

17. de Baère $T$ (2010) Lung Tumor Radiofrequency Ablation: Where Do We Stand? Cardiovasc Intervent Radiol. doi:10.1007/s00270010-0048-Z

18. Lee EW, Suh RD, Zeidler MR, Tsai IS, Cameron RB, Abtin FG, Goldin JG (2009) Radiofrequency ablation of subpleural lung malignancy: reduced pain using an artificially created pneumothorax. Cardiovasc Intervent Radiol 32(4):833-836

19. Anderson EM, Lees WR, Gillams AR (2009) Early indicators of treatment success after percutaneous radiofrequency of pulmonary tumors. Cardiovasc Intervent Radiol 32(3):478-483

20. Zhu JC, Yan TD, Morris DL (2008) A systematic review of radiofrequency ablation for lung tumors. Ann Surg Oncol 15 (6): 1765-1774

21. Omary RA, Bettmann MA, Cardella JF, Bakal CW, Schwartzberg MS, Sacks D, Rholl KS, Meranze SG, Lewis CA, Society of Interventional Radiology Standards of Practice Committee (2003) Quality Improvement Guidelines for the Reporting and Archiving of Interventional Radiology Procedures. J Vasc Interv Radiol 14: S293-S295

22. Okuma T, Matsuoka T, Yamamoto A, Oyama Y, Toyoshima M, Nakamura K, Inoue Y (2008) Frequency and risk factors of various complications after computed tomography-guided radiofrequency ablation of lung tumors. Cardiovasc Intervent Radiol 31 (1): $122-130$

23. Hiraki T, Tajiri N, Mimura H, Yasui K, Gobara H, Mukai T, Hase S, Fujiwara H, Iguchi T, Sano Y, Shimizu N, Kanazawa S (2006) Pneumothorax, pleural effusion, and chest tube placement after radiofrequency ablation of lung tumors: incidence and risk factors. Radiology 241(1):275-283

24. Yamagami $T$, Kato $T$, Hirota $T$, Yoshimatsu R, Matsumoto $T$, Nishimura T (2006) Pneumothorax as a complication of percutaneous radiofrequency ablation for lung neoplasms. J Vasc Interv Radiol 17:1625-1629

25. Sakurai J, Hiraki T, Mukai T, Mimura H, Yasui K, Gobara H, Hase S, Fujiwara H, Iguchi T, Tajiri N, Aoe M, Sano Y, Date H, Kanazawa S (2007) Intractable pneumothorax due to bronchopleural fistula after radiofrequency ablation of lung tumors. J Vasc Interv Radiol 18(1 Pt 1):141-145

26. Yamakado K, Takaki H, Takao M, Murashima S, Kodama H, Kashima M, Nakatsuka A, Uraki J, Shimpo H, Takeda K (2010) Massive hemoptysis from pulmonary artery pseudoaneurysm caused by lung radiofrequency ablation: successful treatment by coil embolization. Cardiovasc Intervent Radiol 33 (2):410-412

27. Crocetti L, Lencioni R (2010) Radiofrequency ablation of pulmonary tumors. Eur J Radiol 75(1):23-27

28. Bojarski JD, Dupuy DE, Mayo-Smith WW (2005) CT imaging findings of pulmonary neoplasms after treatment with radiofrequency ablation: results in 32 tumors. AJR Am J Roentgenol 185(2):466-471

29. Okuma T, Matsuoka T, Yamamoto A, Hamamoto S, Nakamura K, Inoue Y (2009) Assessment of early treatment response after CTguided radiofrequency ablation of unresectable lung tumours by diffusion-weighted MRI: a pilot study. Br J Radiol 82(984):989994
30. Okuma T, Matsuoka T, Okamura T, Wada Y, Yamamoto A, Oyama Y, Koyama K, Nakamura K, Watanabe Y, Inoue Y (2006) 18F-FDG small-animal PET for monitoring the therapeutic effect of CT-guided radiofrequency ablation on implanted VX2 lung tumors in rabbits. J Nucl Med 47 (8):1351-1358

31. Okuma T, Okamura T, Matsuoka T, Yamamoto A, Oyama Y, Toyoshima M, Koyama K, Inoue K, Nakamura K, Inoue Y (2006) Fluorine-18-fluorodeoxyglucose positron emission tomography for assessment of patients with unresectable recurrent or metastatic lung cancers after CT-guided radiofrequency ablation: preliminary results. Ann Nucl Med 20 (2): $115-121$

32. Powell JW, Dexter E, Scalzetti EM, Bogart JA (2009) Treatment advances for medically inoperable non-small-cell lung cancer: emphasis on prospective trials. Lancet Oncol 10 (9):885-894

33. Grieco CA, Simon CJ, Mayo-Smith WW, DiPetrillo TA, Ready NE, Dupuy DE (2006) Percutaneous image-guided thermal ablation and radiation therapy: outcomes of combined treatment for 41 patients with inoperable stage I/II non-small-cell lung cancer. J Vasc Interv Radiol 17(7):1117-1124

34. Dupuy DE, DiPetrillo T, Gandhi S, Ready N, Ng T, Donat W, Mayo-Smith WW (2006) Radiofrequency ablation followed by conventional radiotherapy for medically inoperable stage I nonsmall cell lung cancer. Chest 129(3):738-745

35. Okuma T, Matsuoka T, Yamamoto A, Oyama Y, Hamamoto S, Toyoshima M, Nakamura K, Miki Y (2010) Determinants of local progression after computed tomography-guided percutaneous radiofrequency ablation for unresectable lung tumors: 9-year experience in a single institution. Cardiovasc Intervent Radiol 33 (4):787-793

36. Hiraki T, Sakurai J, Tsuda T, Gobara H, Sano Y, Mukai T, Hase S, Iguchi T, Fujiwara H, Date H, Kanazawa S (2006) Risk factors for local progression after percutaneous radiofrequency ablation of lung tumors: evaluation based on a preliminary review of 342 tumors. Cancer 107(12):2873-2880

37. Gillams AR, Lees WR (2008) Radiofrequency ablation of lung metastases: factors influencing success. Eur Radiol 18(4):672677

38. Pennathur A, Luketich JD, Abbas G, Chen M, Fernando HC, Gooding WE, Schuchert MJ, Gilbert S, Christie NA, Landreneau RJ (2007) Radiofrequency ablation for the treatment of stage I non-small cell lung cancer in high-risk patients. J Thorac Cardiovasc Surg 134(4):857-864

39. Hiraki T, Gobara H, Iishi T, Sano Y, Iguchi T, Fujiwara H, Tajiri N, Sakurai J, Date H, Mimura H, Kanazawa S (2007) Percutaneous radiofrequency ablation for pulmonary metastases from colorectal cancer: midterm results in 27 patients. J Vasc Interv Radiol 18 (10):1264-1269

40. Yamakado $\mathrm{K}$, Inoue $\mathrm{Y}$, Takao $\mathrm{M}$, Takaki $\mathrm{H}$, Nakatsuka $\mathrm{A}$, Uraki J, Kashima M, Kusunoki M, Shimpo H, Takeda K (2009) Long-term results of radiofrequency ablation in colorectal lung metastases: single center experience. Oncol Rep 22(4):885-891

41. Chua TC, Sarkar A, Saxena A, Glenn D, Zhao J, Morris DL (2010) Long-term outcome of image-guided percutaneous radiofrequency ablation of lung metastases: an open-labeled prospective trial of 148 patients. Ann Oncol 21(10):20172022

42. Chua TC, Thornbury K, Saxena A, Liauw W, Glenn D, Zhao J, Morris DL (2010) Radiofrequency ablation as an adjunct to systemic chemotherapy for colorectal pulmonary metastases. Cancer 116(9):2106-2114

43. Pfannschmidt J, Dienemann H, Hoffmann H (2007) Surgical resection of pulmonary metastases from colorectal cancer: a 
systematic review of published series. Ann Thorac Surg 84 (1):324-338

44. Chan VO, McDermott S, Malone DE, Dodd JD (2011) Percutaneous radiofrequency ablation of lung tumors: evaluation of the literature using evidence-based techniques. J Thorac Imaging 26(1):18-26

45. Siva S, MacManus M, Ball D (2010) Stereotactic radiotherapy for pulmonary oligometastases: a systematic review. J Thorac Oncol 5 (7):1091-1099
46. Fakiris AJ, McGarry RC, Yiannoutsos CT et al (2009) Stereotactic body radiation therapy for early-stage non-small-cell lung carcinoma: four-year results of a prospective phase II study. Int $\mathrm{J}$ Radiat Oncol Biol Phys 75:677-682

47. Videtic GM, Stephans KL (2010) The role of stereotactic body radiotherapy in the management of non-small cell lung cancer: an emerging standard for the medically inoperable patient? Curr Oncol Rep 12(4):235-241 